\title{
Correction to: El Niño-related sea surface elevation and ocean bottom pressure enhancement associated with the retreat of the Oyashio southeast of Hokkaido, Japan
}

\author{
Takuya Hasegawa $^{1} \cdot$ Akira Nagano $^{2}$ (D) $\cdot$ Hiroyuki Matsumoto ${ }^{3} \cdot$ Keisuke Ariyoshi $^{3} \cdot$ Masahide Wakita $^{4}$
}

Published online: 24 November 2019

(c) Springer Nature B.V. 2019

\section{Correction to: Marine Geophysical Research https://doi.org/10.1007/s11001-019-09392-8}

In the original publication, the Fig. 2 was published incorrectly. The correct version (Fig. 2) is given in this correction. The original article has been corrected.

Publisher's Note Springer Nature remains neutral with regard to jurisdictional claims in published maps and institutional affiliations.

The original article can be found online at https://doi.org/10.1007/ s11001-019-09392-8.

\section{Akira Nagano \\ nagano@jamstec.go.jp}

1 Graduate School of Science, Tohoku University, 6-3 Aramkai-aza-aoba, Aoba-ku, Sendai 980-8578, Japan

2 Global Ocean Observation Research Center (GOORC), Japan Agency for Marine-Earth Science and Technology (JAMSTEC), 2-15 Natsushima-cho, Yokosuka, Kanagawa 237-0061, Japan

3 Research and Development Center for Earthquake and Tsunami Forecasting (FEAT), JAMSTEC, 3173-25 Showa-machi, Kanazawa-ku, Yokohama, Kanagawa 236-0001, Japan

4 Mutsu Institute for Oceanography (MIO), JAMSTEC, 690 Kitasekine Sekine, Mutsu, Aomori 035-0022, Japan 
Fig. 2 SSH (m) in January from a 2004 to j 2013. Meshing shows regions where $\mathrm{SSH}$ is lower than $0.3 \mathrm{~m}$. OBP stations are indicated by stars

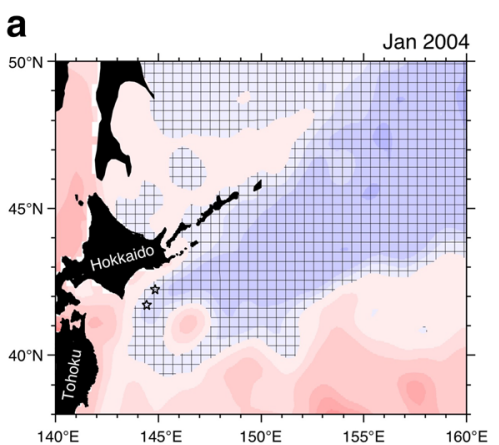

b
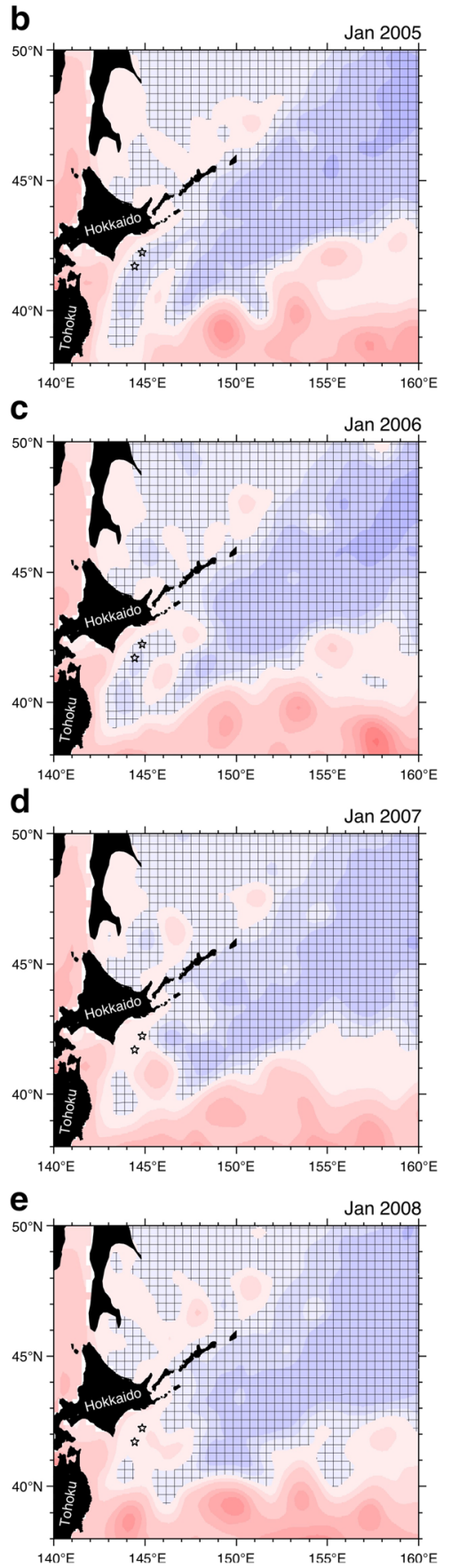

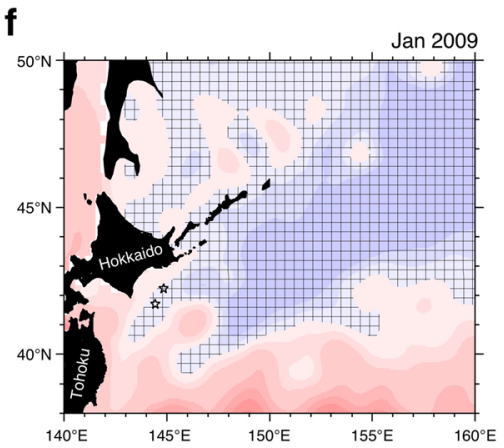

g

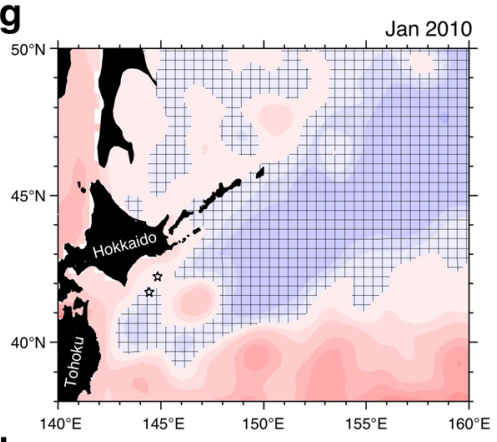

h

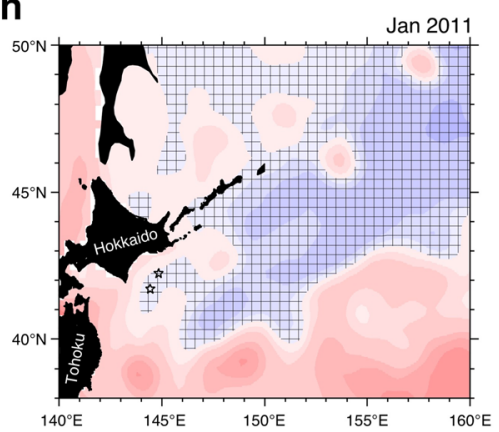

i

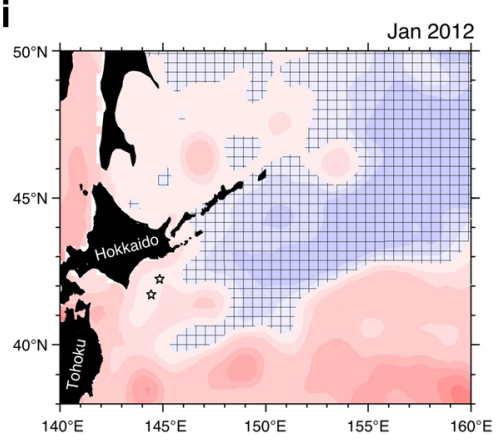

j

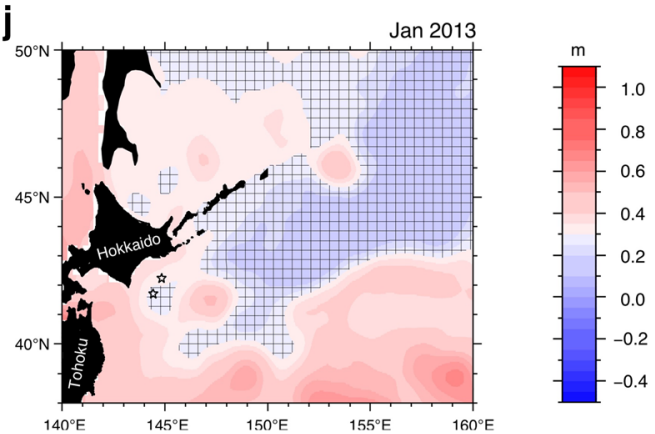

